\title{
Paenibacillus fonticola sp. nov., isolated from a warm spring
}

Jui-Hsing Chou, ${ }^{1}$ Yi-Ju Chou, ${ }^{2}$ Kuan-Yin Lin, ${ }^{2}$ Shih-Yi Sheu, ${ }^{3}$
Der-Shyan Sheu, ${ }^{3}$ A. B. Arun, ${ }^{1}$ Chiu-Chung Young ${ }^{1}$ and Wen-Ming Chen ${ }^{2}$

Correspondence

Wen-Ming Chen

p62365@ms28.hinet.net

\author{
${ }^{1}$ Department of Soil Environmental Science, College of Agriculture and Natural Resources, \\ National Chung Hsing University, Taichung, Taiwan \\ ${ }^{2}$ Laboratory of Microbiology, Department of Seafood Science, National Kaohsiung Marine \\ University, No. 142, Hai-Chuan Rd. Nan-Tzu, Kaohsiung City 811, Taiwan \\ ${ }^{3}$ Department of Marine Biotechnology, National Kaohsiung Marine University, Kaohsiung, \\ Taiwan
}

\begin{abstract}
A novel bacterial strain, designated $\mathrm{ZL}^{\top}$, isolated from a warm spring in Jhonglun, Taiwan, was characterized by using a polyphasic taxonomic approach. The novel strain had chemotaxonomic and morphological properties consistent with its classification in the genus Paenibacillus. Cells were Gram-variable, aerobic, sporulating, motile rods. 16S rRNA gene sequence analysis demonstrated that this novel isolate was unique, showing $94.3 \%$ sequence similarity to Paenibacillus assamensis GPTSA $11^{\top}$ and lower levels to Paenibacillus timonensis $2301032^{\top}$ (94.0\%), Paenibacillus macerans ATCC $8244^{\top}$ (93.3\%), Paenibacillus barengoltzii SAFN-016 ${ }^{\top}$ (93.3\%) and Paenibacillus sanguinis $2301083^{\top}$ (93.2 \%). The novel isolate could be distinguished from the type strains of all of these species based on a range of phenotypic data. The major cellular phospholipids were phosphatidylglycerol, diphosphatidylglycerol, phosphatidylethanolamine and one unknown phosphoglycolipid. The predominant isoprenologue was an unsaturated menaquinone with seven isoprene units (MK-7). The major fatty acids of strain $\mathrm{ZL}^{\top}$ were $\mathrm{C}_{16: 0}$ (33.5\%), anteiso- $\mathrm{C}_{15: 0}(32.5 \%)$ and iso- $\mathrm{C}_{16: 0}(9.3 \%)$. The $\mathrm{G}+\mathrm{C}$ content of the genomic DNA was $49.2 \mathrm{~mol} \%$. It is evident from the genotypic and phenotypic data that strain $\mathrm{ZL}^{\top}$ should be classified as representing a novel species of the genus Paenibacillus, for which the name Paenibacillus fonticola sp. nov. is proposed. The type strain is $\mathrm{ZL}^{\top}$ (=BCRC $17579^{\top}=\mathrm{LMG}$ $23577^{\top}$ ).
\end{abstract}

The genus Paenibacillus was erected by Ash et al. (1993) to accommodate 11 species previously assigned to the genus Bacillus. Since then, many novel Paenibacillus species have been described. At the time of writing, more than 60 species are recognized as members of the genus (http://www.bacterio.cict.fr/p/paenibacillus.html). Species belonging to the genus Paenibacillus have been isolated from various ecological niches such as soil, rhizospheres, phyllospheres, water, insects, food, faeces, blood cultures and Antarctic sediments (Saha et al., 2005). A few Paenibacillus species have been isolated from human biological samples and the possibility that these bacteria may cause human infection is of particular concern (Roux \& Raoult, 2004). Generally,

The GenBank/EMBL/DDBJ accession number for the 16S rRNA gene sequence of strain $Z^{\top}$ is $D Q 453131$.

Neighbour-joining and maximum-parsimony phylogenetic trees based on $16 \mathrm{~S}$ rRNA gene sequences showing the position of strain $\mathrm{ZL}^{\top}$ within the genus Paenibacillus are available as supplementary figures with the online version of this paper. members of this genus produce endospores, possess anteiso- $\mathrm{C}_{15: 0}$ as the major cellular fatty acid and have genomic DNA G $+C$ contents in the range 39-54 mol\% (Shida et al., 1997a; Saha et al., 2005).

The aim of the present study was to determine the taxonomic position of a novel Paenibacillus-like organism, designated strain $\mathrm{ZL}^{\mathrm{T}}$, by using a polyphasic taxonomic approach.

In January 2006, strain $\mathrm{ZL}^{\mathrm{T}}$ was isolated from a water sample collected from Jhonglun warm spring in Chiayi County, Taiwan. The temperature of the spring water ranged between 35 and $45^{\circ} \mathrm{C}$ and the $\mathrm{pH}$ was between 7 and 8 . The water sample was diluted with sterile distilled water and vortexed thoroughly. Appropriate dilutions were then plated on trypticase soy broth agar and incubated at $42{ }^{\circ} \mathrm{C}$ for 2 days. The majority of colonies (>99\%) showed identical morphology.

The optimum $\mathrm{pH}$ range for growth was examined in trypticase soy broth by using appropriate biological buffers 
(pH 3-11) (Chung et al., 1995). The optimum temperature for growth $\left(15-60{ }^{\circ} \mathrm{C}\right)$ of the novel strain was examined in trypticase soy broth adjusted to $\mathrm{pH} 7$. Growth was examined by measuring the turbidity $\left(\mathrm{OD}_{600}\right)$ of cultures grown at various $\mathrm{pH}$ values and temperatures. Anaerobic cultivation was performed on nutrient agar and trypticase soy broth agar by using an Oxoid AnaeroGen system.

Strain $\mathrm{ZL}^{\mathrm{T}}$ showed good growth on complex media, such as trypticase soy broth, nutrient agar and LB medium. Strain $\mathrm{ZL}^{\mathrm{T}}$ formed visible, cream/white-coloured, semi-transparent colonies of a circular shape with entire edges. Colonies were approximately $0.3-0.5 \mathrm{~mm}$ in diameter after $48 \mathrm{~h}$ incubation at $42{ }^{\circ} \mathrm{C}$. Strain $\mathrm{ZL}^{\mathrm{T}}$ showed good growth at temperatures ranging from 20 to $45^{\circ} \mathrm{C}$ and $\mathrm{pH} 7$ and 10 . Optimal growth was seen at $35-42^{\circ} \mathrm{C}$ and $\mathrm{pH}$ 8.0-9.0.

Cells were observed in the lag exponential and stationary phases of growth under a phase-contrast microscope to ascertain shape and motility (using the hanging-drop technique). Flagellum staining was performed by using Spot Test Flagella Stain (BD Difco). Gram Stain Set S (BD) and the Ryu non-staining $\mathrm{KOH}$ method (Powers, 1995) were used to ascertain the Gram reaction. Poly- $\beta$-hydroxybutyrate granule accumulation was observed under light microscopy after staining cells with Sudan black.

Cells of strain $\mathrm{ZL}^{\mathrm{T}}$ stained Gram-variable and were straight rods $(0.8-1.0 \mu \mathrm{m}$ wide and $2.0-12.4 \mu \mathrm{m}$ long). Sporeforming cells were rare (endospores). Terminal or subterminal ellipsoidal spores were observed in non-swollen or slightly swollen sporangia. Cells were motile by means of peritrichous flagella. No accumulation of poly- $\beta$-hydroxybutyrate granules was observed.

Extraction of genomic DNA, PCR amplification and sequencing of $16 \mathrm{~S}$ rRNA genes were carried out as described by Chen et al. (2001). Sequence analysis was performed with a DNA sequencer (ABI PRISM 310; Applied Biosystems) and the Fragment Assembly System program from the Wisconsin Package 9.1 (Genetics Computer Group, 1995) supplied by the National Health Research Institute of Taiwan. The resultant sequence was compared with the corresponding results taken from the EMBL, GenBank and RDP II databases for representatives of the genera classified in the order Bacillales. Multiple-sequence alignment of strain $\mathrm{ZL}^{\mathrm{T}}$ with its closest relatives was performed by using BioEdit software (Hall, 1999) and MEGA version 3.1 (Kumar et al., 2004). Phylogenetic trees were inferred using the maximum-likelihood (Felsenstein, 1981), maximumparsimony (Kluge \& Farris, 1969) and neighbour-joining (Saitou \& Nei, 1987) algorithms. Unrooted tree topologies were evaluated by bootstrap analyses of the neighbourjoining data set (Felsenstein, 1993). An almost complete $16 \mathrm{~S}$ rRNA gene sequence (1464 nt) was obtained for strain $\mathrm{ZL}^{\mathrm{T}}$. A comparison of this sequence with those of representatives of the genera classified in the order Bacillales showed that the novel organism fell within the evolutionary radiation occupied by the genus Paenibacillus. Maximum 16S rRNA gene sequence similarity between strain $\mathrm{ZL}^{\mathrm{T}}$ and the type strains of recognized members of the genus Paenibacillus was $94.3 \%$.

It is evident from the phylogenetic tree based on the neighbour-joining algorithm that strain $\mathrm{ZL}^{\mathrm{T}}$ clearly forms a monophyletic branch in the genus Paenibacillus (see Fig. 1 and Supplementary Fig. S1 available in IJSEM Online). The organism was most closely related to Paenibacillus assamensis GPTSA $11^{\mathrm{T}}$, sharing a $16 \mathrm{~S}$ rRNA gene sequence similarity of $94.3 \%$. Strain $\mathrm{ZL}^{\mathrm{T}}$ also shared comparatively low 16S rRNA gene sequence similarity with Paenibacillus timonensis $2301032^{\mathrm{T}}(94.0 \%)$, Paenibacillus macerans ATCC $8244^{\mathrm{T}}(93.3 \%)$, Paenibacillus barengoltzii SAFN$016^{\mathrm{T}} \quad(93.3 \%)$ and Paenibacillus sanguinis $2301083^{\mathrm{T}}$ $(93.2 \%)$. Similar tree topologies were obtained in phylogenetic trees generated with the maximum-parsimony (see Supplementary Fig. S2 in IJSEM Online) and maximumlikelihood algorithms (data not shown).

DNA-DNA relatedness experiments were not performed between strain $\mathrm{ZL}^{\mathrm{T}}$ and its closest phylogenetic neighbours as the level of $16 \mathrm{~S}$ rRNA gene sequence similarity between strain $\mathrm{ZL}^{\mathrm{T}}$ and other Paenibacillus species was less than $95 \%$ and thus below the cut-off value (97\%) suggested by Stackebrandt \& Goebel (1994) for genomic distinction of species.

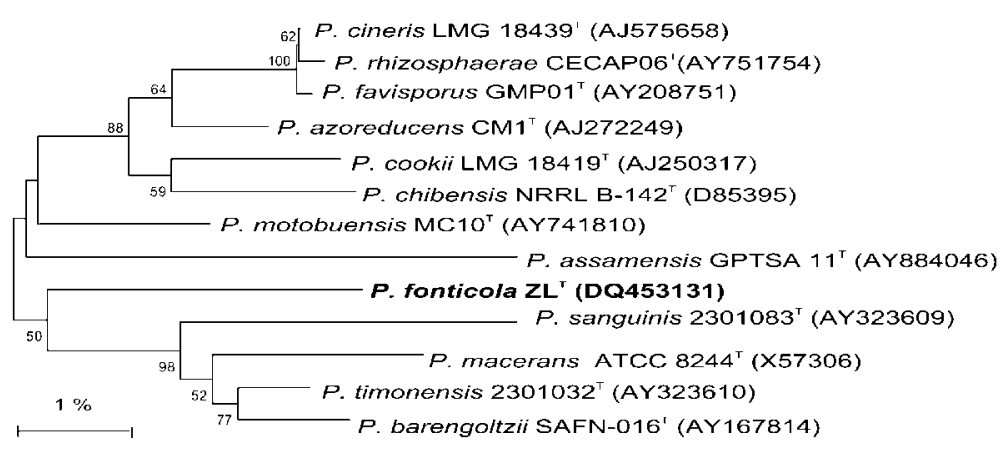

Fig. 1. Phylogenetic analysis based on $16 \mathrm{~S}$ rRNA gene sequences available from the European Molecular Biology Laboratory database (accession numbers are given in parentheses) constructed after multiple alignments of data showing the position of strain $\mathrm{ZL}^{\top}$ within the genus Paenibacillus. Distances and clustering with the neighbourjoining method were performed by using the BioEdit software package. Numbers at nodes are percentage bootstrap values based on 1000 resampled datasets; only values above $50 \%$ are given. Bar, $1 \%$ sequence dissimilarity per nucleotide position. 
The DNA G $+\mathrm{C}$ content was determined in duplicate as described by Mesbah et al. (1989). The DNA G + C content of strain $\mathrm{ZL}^{\mathrm{T}}$ was $49.2( \pm 1.2)$ mol\% (mean $\left.\pm \mathrm{SD}\right)$.

Chemotaxonomic studies were performed to establish whether strain $\mathrm{ZL}^{\mathrm{T}}$ had a chemical profile consistent with its assignment within the genus Paenibacillus. Biomass for chemical studies was grown in shake flasks of trypticase soy broth for 5 days at $37^{\circ} \mathrm{C}$, checked for purity, harvested by centrifugation, washed twice in distilled water and freezedried. Polar lipids were extracted and analysed by twodimensional TLC as described by Ventosa et al. (1993). The major cellular phospholipids were phosphatidylglycerol, diphosphatidylglycerol, phosphatidylethanolamine and one unknown phosphoglycolipid. Respiratory quinones of strain $\mathrm{ZL}^{\mathrm{T}}$ were extracted, separated and identified as described by Saha et al. (2005). The predominant isoprenologue was unsaturated menaquinone with seven isoprene units (MK-7). The diagnostic cell-wall amino acid of strain $\mathrm{ZL}^{\mathrm{T}}$ was determined by TLC (Staneck \& Roberts, 1974). The isolate contained meso-diaminopimelic acid (wall chemotype III). Cellular fatty acids were analysed as methyl esters by GC according to the instructions of the Microbial Identification System (MIDI; Microbial ID). The predominant fatty acids of strain $\mathrm{ZL}^{\mathrm{T}}$ were $\mathrm{C}_{16: 0}$, anteiso- $\mathrm{C}_{15: 0}$ and iso- $\mathrm{C}_{16: 0}$. All of these properties are typical of representatives of the genus Paenibacillus (Shida et al., 1997a). The fatty acid profile of strain $\mathrm{ZL}^{\mathrm{T}}$ was generally comparable with those of the type strains of $P$. assamensis, $P$. timonensis, $P$. macerans and P. sanguinis (Shida et al., 1997b; Roux \& Raoult, 2004; Saha et al., 2005), but differed in the proportions of certain fatty acids (Table 1). Strain $\mathrm{ZL}^{\mathrm{T}}$ contained higher amounts of $\mathrm{C}_{16: 0}(33.5 \%)$ and $\mathrm{C}_{14: 0}(7.5 \%)$, a feature that enabled the novel strain to be clearly distinguished from $P$. assamensis, $P$. timonensis, $P$. macerans and $P$. sanguinis.

Strain $\mathrm{ZL}^{\mathrm{T}}$ was examined for a broad range of phenotypic and biochemical properties by using the API 20E, API 20NE, API ZYM (bioMérieux) and Microlog GN2 (Biolog) systems according to the manufacturers' instructions. Additionally, the sensitivity of strain $\mathrm{ZL}^{\mathrm{T}}$ to different antibiotics was checked by using antibiotic discs (Oxoid).

Detailed results of the biochemical characterization and antibiotic sensitivity tests are given in Table 2 and in the species description below. It is apparent from the results (Table 2) that strain $\mathrm{ZL}^{\mathrm{T}}$ can be distinguished from representatives of its close phylogenetic relatives by using a combination of phenotypic attributes, especially ONPG hydrolysis, nitrate reduction, the Voges-Proskauer reaction, optimum temperature for growth, acid production from various sugars (such as glucose, mannitol, arabinose, inositol, rhamnose and sucrose) and enzyme activities (catalase, oxidase and gelatinase).

It is clear from the genotypic and phenotypic data presented that strain $\mathrm{ZL}^{\mathrm{T}}$ represents a novel species of the genus Paenibacillus, for which the name Paenibacillus fonticola sp. nov. is proposed.
Table 1. Whole-cell fatty acid contents (\% of total fatty acids) of strain $\mathrm{ZL}^{\top}$ and related species of the genus Paenibacillus

Taxa: 1, strain $\mathrm{ZL}^{\mathrm{T}} ; 2$, P. macerans ATCC $8244^{\mathrm{T}} ; 3$, P. sanguinis $2301083^{\mathrm{T}}$; 4, P. timonensis $2301032^{\mathrm{T}}$; 5 , P. assamensis GPTSA $11^{\mathrm{T}}$. Data for $P$. macerans, $P$. sanguinis, $P$. timonensis and $P$. assamensis were obtained from Shida et al. (1997b), Roux \& Raoult (2004) and Saha et al. (2005). No fatty acid data are available for $P$. barengoltzii SAFN-016 ${ }^{\mathrm{T}}$ (Osman et al., 2006). Fatty acid values of $<1 \%$ are not shown.

\begin{tabular}{|c|c|c|c|c|c|}
\hline Fatty acid & 1 & 2 & 3 & 4 & 5 \\
\hline $\mathrm{C}_{14: 0}$ & 7.5 & 3.7 & & 1.3 & 1.8 \\
\hline $\mathrm{C}_{15: 0}$ & & & 2.8 & 2.0 & \\
\hline $\mathrm{C}_{16: 0}$ & 33.5 & 17.9 & 10.1 & 10.6 & 3.5 \\
\hline $\mathrm{C}_{17: 0}$ & & & & & 1.6 \\
\hline iso- $\mathrm{C}_{14: 0}$ & 3.6 & 7.9 & 1.7 & 8.2 & 4.7 \\
\hline iso- $\mathrm{C}_{15: 0}$ & 5.7 & 2.6 & 6.8 & 10.1 & 6.0 \\
\hline iso- $\mathrm{C}_{16: 0}$ & 9.3 & 16.4 & 13.4 & 15.5 & 11.6 \\
\hline iso- $\mathrm{C}_{17: 0}$ & 2.0 & & 5.8 & 1.9 & 1.6 \\
\hline anteiso- $\mathrm{C}_{15: 0}$ & 32.5 & 36.1 & 44.2 & 43.4 & 48.4 \\
\hline anteiso- $\mathrm{C}_{17: 0}$ & 2.8 & 12.2 & 6.8 & 4.0 & 5.7 \\
\hline $\mathrm{C}_{16: 1} \omega 11 c$ & 1.5 & & & & 6.2 \\
\hline $\mathrm{C}_{16: 1} \omega 7 c$ alcohol & & & & & 5.0 \\
\hline iso- $\mathrm{C}_{17: 1} \omega 10 c$ & & & & & 1.2 \\
\hline Summed feature $1^{\star}$ & & & & & 1.6 \\
\hline
\end{tabular}

${ }^{*}$ Summed feature 1 comprises iso- $\mathrm{C}_{17: 1} \mathrm{I}$ and/or anteiso- $\mathrm{C}_{17: 1}$.

\section{Description of Paenibacillus fonticola sp. nov.}

Paenibacillus fonticola (fon.ti.co'la. L. masc. n. fons fontis a spring, fountain; L. suf. -cola from L. masc. or fem. n. incola an inhabitant of a place, a resident; N.L. n. fonticola an inhabitant of a fountain).

Cells are facultatively anaerobic, Gram-variable, sporulating, motile, rod-shaped, $0.8-1.0 \mu \mathrm{m}$ in diameter and 2.0 $12.4 \mu \mathrm{m}$ in length. Grows at $\mathrm{pH} 7-10$ and at $20-45^{\circ} \mathrm{C}$. Positive (API 20NE and 20E) for catalase, urease, aesculin hydrolysis, gelatin hydrolysis, $\beta$-galactosidase, OPNG test, gelatinase and acid production from arabinose. Negative for oxidase, nitrate reduction, indole production, glucose fermentation, arginine dihydrolase, assimilation of D-glucose, L-arabinose, D-mannose, D-mannitol, $\mathrm{N}$-acetylglucosamine, D-maltose, gluconate, caprate, adipate, malate, citrate, phenylacetate, lysine decarboxylase and ornithine decarboxylase, citrate utilization, $\mathrm{H}_{2} \mathrm{~S}$ production, tryptophan deaminase, acetoin production and acid production from glucose, mannitol, inositol, sorbitol, rhamnose, sucrose, melibiose and amygdalin. In API ZYM enzyme reactions, positive for C4 esterase, naphthol-AS-BI-phosphohydrolase, $\alpha$-galactosidase and $\beta$-galactosidase, but negative for alkaline phosphatase, C8 lipase, C14 lipase, leucine arylamidase, valine arylamidase, cystine arylamidase, trypsin, $\alpha$-chymotrypsin, acid phosphatase, $\beta$-glucuronidase, $\alpha$-glucosidase, $\beta$-glucosidase, $N$-acetyl- $\beta$-glucosaminidase, $\alpha$-mannosidase 
Table 2. Phenotypic and biochemical characteristics that differentiate strain $\mathrm{ZL}^{\top}$ from representatives of closely related species of the genus Paenibacillus

Taxa: 1, strain $\mathrm{ZL}^{\mathrm{T}}$; 2, P. macerans ATCC $8244^{\mathrm{T}}$; 3, P. sanguinis $2301083^{\mathrm{T}} ; 4$, P. timonensis $2301032^{\mathrm{T}}$; 5, P. assamensis GPTSA $11^{\mathrm{T}}$; 6 , P. barengoltzii SAFN-016 ${ }^{\mathrm{T}}$. Data for P. macerans, P. sanguinis, P. timonensis, P. assamensis, P. barengoltzii are taken from Shida et al. (1997b), Roux \& Raoult (2004), Saha et al. (2005) and Osman et al. (2006). +, Positive; -, negative; W, weak response; ND, no data.

\begin{tabular}{|c|c|c|c|c|c|c|}
\hline Characteristic & 1 & 2 & 3 & 4 & 5 & 6 \\
\hline Isolation source & Warm spring & ND & Human blood & Human blood & Warm spring & Spacecraft assembly facility \\
\hline Catalase & + & + & - & + & + & + \\
\hline ONPG hydrolysis & + & + & ND & ND & - & + \\
\hline Growth at $50{ }^{\circ} \mathrm{C}$ & - & + & - & + & - & + \\
\hline Nitrate reduction & - & + & - & $\mathrm{W}$ & - & + \\
\hline Voges-Proskauer test & - & + & - & - & - & + \\
\hline Gelatinase & + & - & - & - & + & - \\
\hline \multicolumn{7}{|l|}{ Acid production from: } \\
\hline Amygdalin & - & ND & + & + & $\mathrm{W}$ & ND \\
\hline Melibiose & - & ND & + & + & - & - \\
\hline Rhamnose & - & + & - & - & - & - \\
\hline Sucrose & - & + & + & - & $\mathrm{W}$ & - \\
\hline DNA G $+\mathrm{C}$ content $(\mathrm{mol} \%)$ & 49.2 & 52.2 & ND & $\mathrm{ND}$ & 41.2 & ND \\
\hline
\end{tabular}

and $\alpha$-fucosidase. The following carbon sources are oxidized (positive in the Biolog GN2 system): dextrin, Tween 80, D-cellobiose, D-fructose, $\alpha$-D-glucose, D-mannose, D-melibiose, sucrose and D-trehalose. The following substrates are not utilized as carbon sources (negative in the Biolog GN2 system): $\alpha$-cyclodextrin, glycogen, Tween 40, $N$ acetyl-D-galactosamine, $\mathrm{N}$-acetyl-D-glucosamine, adonitol, L-arabinose, D-arabitol, i-erythritol, L-fucose, D-galactose, gentiobiose, myo-inositol, $\alpha$-D-lactose, lactulose, maltose, D-mannitol, methyl $\beta$-D-glucoside, D-psicose, D-raffinose, L-rhamnose, D-sorbitol, turanose, xylitol, methyl pyruvate, monomethyl succinate, acetic acid, cis-aconitic acid, citrate, formic acid, D-galactonic acid lactone, D-galacturonic acid, D-gluconate, D-glucosaminic acid, D-glucuronic acid, $\alpha$-hydroxybutyric acid, $\beta$-hydroxybutyric acid, $\gamma$-hydroxybutyric acid, $p$-hydroxyphenylacetic acid, itaconic acid, $\alpha$-ketovaleric acid, $\alpha$-ketobutyric acid, $\alpha$-ketoglutaric acid, DL-lactate, malonic acid, propionic acid, quinic acid, D-saccharic acid, sebacic acid, succinic acid, bromosuccinic acid, succinamic acid, glucuronamide, L-alaninamide, Dalanine, L-alanine, L-alanyl glycine, L-asparagine, L-aspartic acid, L-glutamic acid, glycyl L-aspartic acid, glycyl L-glutamic acid, L-histidine, hydroxy-L-proline, L-leucine, L-ornithine, L-phenylalanine, L-proline, L-pyroglutamic acid, D-serine, L-serine, L-threonine, DL-carnitine, $\gamma$-aminobutyric acid, urocanic acid, inosine, uridine, thymidine, phenylethylamine, putrescine, 2-aminoethanol, 2,3-butanediol, glycerol, DL- $\alpha$-glycerol phosphate, glucose 1-phosphate and glucose 6-phosphate. Sensitive to ampicillin $(10 \mu \mathrm{g})$, cefotaxime $(30 \mu \mathrm{g})$, chloramphenicol $(30 \mu \mathrm{g})$, gentamicin $(10 \mu \mathrm{g})$, kanamycin $(30 \mu \mathrm{g})$, nalidixic acid $(30 \mu \mathrm{g})$, novobiocin $(30 \mu \mathrm{g})$, penicillin $\mathrm{G}(10 \mathrm{U})$, rifampicin $(5 \mu \mathrm{g})$, streptomycin $(10 \mu \mathrm{g})$ and tetracycline $(30 \mu \mathrm{g})$. The major fatty acids are $\mathrm{C}_{16: 0}$, anteiso- $\mathrm{C}_{15: 0}$ and iso- $\mathrm{C}_{16: 0}$. The $\mathrm{G}+\mathrm{C}$ content of the DNA is $49.2 \mathrm{~mol} \%$.

The type strain, $\mathrm{ZL}^{\mathrm{T}}\left(=\mathrm{BCRC} 17579^{\mathrm{T}}=\mathrm{LMG} 23577^{\mathrm{T}}\right)$, was isolated from a water sample collected from Jhonglun warm spring, Chiayi County, Taiwan.

\section{References}

Ash, C., Priest, F. G. \& Collins, M. D. (1993). Molecular identification of rRNA group 3 bacilli (Ash, Farrow, Wallbanks and Collins) using a PCR probe test. Proposal for the creation of a new genus Paenibacillus. Antonie van Leeuwenhoek 64, 253-260.

Chen, W. M., Laevens, S., Lee, T. M., Coenye, T., de Vos, P., Mergeay, M. \& Vandamme, P. (2001). Ralstonia taiwanensis sp. nov., isolated from root nodules of Mimosa species and sputum of a cystic fibrosis patient. Int J Syst Evol Microbiol 51, 1729-1735.

Chung, Y. C., Kobayashi, T., Kanai, H., Akiba, T. \& Kudo, T. (1995). Purification and properties of extracellular amylase from the hyperthermophilic archaeon Thermococccus profundus DT5432. Appl Environ Microbiol 61, 1502-1506.

Felsenstein, J. (1981). Evolutionary trees from DNA sequences: a maximum likelihood approach. J Mol Evol 17, 368-376. 
Felsenstein, J. (1993). PHYLIP (phylogeny inference package), version 3.5c. Department of Genome Sciences, University of Washington, Seattle, USA.

Genetics Computer, Group. (1995). Wisconsin Package Version 8.1 Program Manual. Madison, WI: Genetics Computer Group.

Hall, T. A. (1999). BioEdit: a user-friendly biological sequence alignment editor and analysis program for Windows 95/98/NT. Nucleic Acids Symp Ser 41, 95-98.

Kluge, A. G. \& Farris, F. S. (1969). Quantitative phyletics and the evolution of anurans. Syst Zool 18, 1-32.

Kumar, S., Tamura, K. \& Nei, M. (2004). MEGA3: integrated software for molecular evolutionary genetics analysis and sequence alignment. Brief Bioinform 5, 150-163.

Mesbah, M., Premachandran, U. \& Whitman, W. B. (1989). Precise measurement of the $\mathrm{G}+\mathrm{C}$ content of deoxyribonucleic acid by high-performance liquid chromatography. Int J Syst Bacteriol 39, 159-167.

Osman, S., Satomi, M. \& Venkateswaran, K. (2006). Paenibacillus pasadenensis sp. nov. and Paenibacillus barengoltzii sp. nov., isolated from a spacecraft assembly facility. Int J Syst Evol Microbiol 56, 1509-1514.

Powers, E. M. (1995). Efficacy of the Ryu nonstaining $\mathrm{KOH}$ technique for rapidly determining gram reactions of food-borne and waterborne bacteria and yeasts. Appl Environ Microbiol 61, 3756-3758.

Roux, V. \& Raoult, D. (2004). Paenibacillus massiliensis sp. nov., Paenibacillus sanguinis sp. nov. and Paenibacillus timonensis sp. nov., isolated from blood cultures. Int J Syst Evol Microbiol 54, 1049-1054.
Saha, P., Mondal, A. K., Mayilraj, S., Krishnamurthi, S., Bhattacharya, A. \& Chakrabarti, T. (2005). Paenibacillus assamensis sp. nov., a novel bacterium isolated from a warm spring in Assam, India. Int J Syst Evol Microbiol 55, 2577-2581.

Saitou, N. \& Nei, M. (1987). The neighbor-joining method: a new method for constructing phylogenetic trees. Mol Biol Evol 4, 406-425.

Shida, O., Takagi, H., Kadowaki, K., Nakamura, L. K. \& Komagata, K. (1997a). Transfer of Bacillus alginolyticus, Bacillus chondroitinus, Bacillus curdlanolyticus, Bacillus glucanolyticus, Bacillus kobensis, and Bacillus thiaminolyticus to the genus Paenibacillus and emended description of the genus Paenibacillus. Int J Syst Bacteriol 47, 289-298.

Shida, O., Takagi, H., Kadowaki, K., Nakamura, L. K. \& Komagata, K. (1997b). Emended description of Paenibacillus amylolyticus and description of Paenibacillus illinoisensis sp. nov. and Paenibacillus chibensis sp. nov. Int J Syst Bacteriol 47, 299-306.

Stackebrandt, E. \& Goebel, B. M. (1994). Taxonomic note: a place for DNA-DNA reassociation and 16S rRNA sequence analysis in the present species definition in bacteriology. Int J Syst Bacteriol 44, 846-849.

Staneck, J. L. \& Roberts, G. D. (1974). Simplified approach to identification of aerobic actinomycetes by thin-layer chromatography. Appl Microbiol 28, 226-231.

Ventosa, A., Marquez, M. C., Kocur, M. \& Tindall, B. J. (1993). Comparative study of "Micrococcus sp." strains CCM 168 and CCM 1405 and members of the genus Salinicoccus. Int J Syst Bacteriol 43, 245-248. 